\title{
Editorial
}

\section{Kreative Auszeit}

_ An einem Tag im Jahr nimmt unser Team von ergopraxis eine kreative Auszeit. Dann verlassen wir unsere Schreibtische, organisieren viel Kaffee und Nervennahrung und laden Ergotherapeuten aus Praxis, Ausbildung oder Studium ein oder einfach Menschen, von denen wir uns gute Impulse erhoffen. Immer mit dabei sind Sie. Und zwar in Form von E-Mails, Umfrageergebnissen oder Erinnerungen aus Gesprächen, in denen Sie uns wertvolle Rückmeldungen zu ergopraxis gegeben haben.

_ Mit diesen Inspirationen im Gepäck bzw. auf dem Tisch spinnen wir neue Ideen, hinterfragen Altes und feilen an unserem Konzept. Ich schätze an diesen Auszeit-

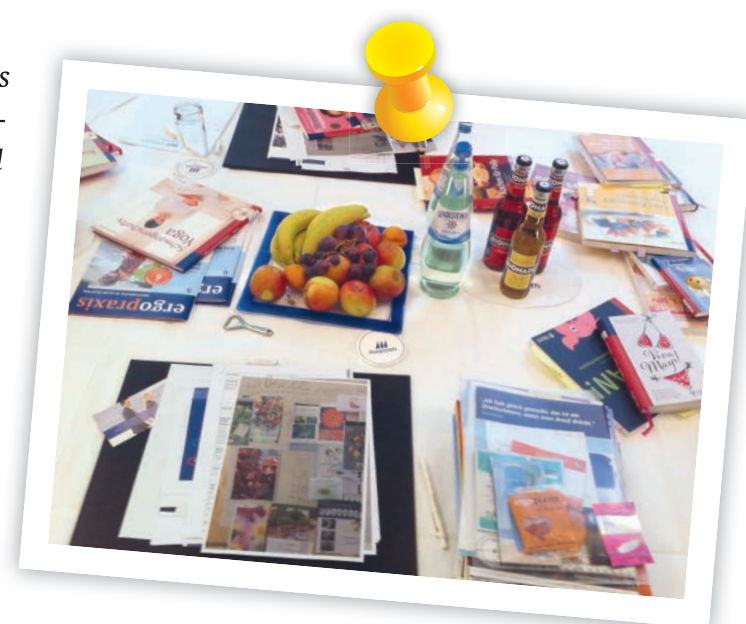
Tagen, dass sie den Arbeitsalltag unterbrechen, die Sinne schärfen und das gesamte Team wieder auf einen gemeinsamen Kurs bringen. Denn der kann im Lauf der Zeit ganz unbemerkt eine andere Richtung einschlagen, oder das Team verändert sich.

_ An solchen Tagen haben wir schon viele Formate ins Leben gerufen, zum Beispiel „Die Rechtsfrage“, „Die wichtigsten Strategien bei ...“ oder „Im Test“. Auf die Neuerungen, die wir uns dieses Mal ausgedacht haben, dürfen Sie schon jetzt gespannt sein. Sie werden Ihnen im Lauf der nächsten Ausgaben begegnen. Was Sie davon halten, interessiert uns natürlich sehr. Und wer weiß, vielleicht ist Ihre Rückmeldung bei unserer nächsten Auszeit der Auslöser für etwas ganz Großes ...

Herzlichst

Ihre

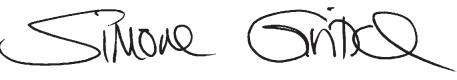

